\title{
Changes in HER2 Expression and Amplification Status Following Preoperative Chemotherapy for Gastric Cancer
}

\author{
SEI SHU ${ }^{1,2}$, MAKOTO IIMORI $^{3}$, RYOTA NAKANISHI $^{1}$, TOMOKO JOGO $^{1}$, \\ HIROSHI SAEKI ${ }^{1}$, EIJI OKI ${ }^{1}$ and YOSHIHIKO MAEHARA ${ }^{1,4}$ \\ ${ }^{1}$ Department of Surgery and Science, Graduate School of Medical Sciences, and \\ ${ }^{3}$ Department of Molecular Cancer Biology, Graduate School of Pharmaceutical Sciences, \\ Kyushu University, Kyushu University, Fukuoka, Japan; \\ ${ }^{2}$ Product Research Department, Medical Affairs Division, Chugai Pharmaceutical Co., Ltd., Kamakura, Japan; \\ ${ }^{4}$ Kyushu Central Hospital of the Mutual Aid Association of Public School Teachers, Fukuoka, Japan
}

\begin{abstract}
Background: It is essential to establish a strategy for second-line treatment for human epidermal growth factor receptor 2 (HER2)-positive gastric cancer; however, HER2 expression status after chemotherapy treatment is not routinely determined. Materials and Methods: We analyzed 25 cases of gastric cancer that received preoperative chemotherapy and selected the six pre-treatment samples that were HER2positive. Pre- and post-treatment tumor samples were examined for HER2 expression, and for HER2, epidermal growth factor receptor (EGFR), and hepatocyte growth factor receptor (MET) gene amplification. Results: Three patients had been treated with trastuzumab plus chemotherapy, and three patients with cytotoxic chemotherapy alone. Only one case that had an initial HER2 score of 3+ and had received trastuzumab plus chemotherapy remained HER2-positive after treatment. Decrease or loss of HER2 expression and amplification was observed in the other five patients. Amplification of EGFR or MET was not observed in any preor post-treatment specimens. Conclusion: Our data suggest that trastuzumab plus chemotherapy or chemotherapy alone may induce loss of HER2 positivity.
\end{abstract}

Approximately $10-30 \%$ of gastric cancer cases are human epidermal growth factor receptor 2 (HER2)-positive and are possible targets for anti-HER2 therapy (1-5). The phase III Trastuzumab for Gastric Cancer (ToGA) study was the first trial to demonstrate a significant therapeutic benefit of

This article is freely accessible online.

Correspondence to: Eiji Oki, MD, Ph.D., 3-1-1 Maidashi, Higashiku, Fukuoka 812-8582, Japan. Tel: +81 926425466, Fax: +81 926425482, e-mail: okieiji@surg2.med.kyushu-u.ac.jp

Key Words: HER2, gastric cancer, trastuzumab. trastuzumab, a humanized monoclonal antibody to HER2, in combination with chemotherapy against HER2-positive gastric or gastro-esophageal junction cancer (6). Regarding secondline treatment, the efficacy of continuous anti-HER2-targeted therapy has been investigated. In the TyTAN trial, which explored the efficacy of lapatinib for the second-line treatment of HER2-positive advanced gastric cancer, the addition of lapatinib to second-line paclitaxel was not superior compared to placebo plus paclitaxel (7). In the GATSBY trial, trastuzumab emtansine (T-DM1) was not superior to taxane monotherapy in patients with previously treated HER2positive gastric or gastro-esophageal junction cancer (8). It is also noteworthy that in the GATSBY trial, T-DM1 failed to prove its superiority over taxane in patients who had received cytotoxic therapy alone $(23 \%)$ and in those who had been previously treated with HER2-targeted therapy (77\%) (8).

Mechanisms to explain these disappointing results have been proposed. One explanation is that HER2 positivity is lost after HER2-targeted treatment. In breast and gastric cancer, it has been reported that previously treated tumors may lose HER2 expression after HER2-targeted therapy (913). The selective pressure of HER2-targeted treatment has been proposed as one of the mechanisms whereby HER2 expression is lost. Since trastuzumab exerts its antitumor effects against HER2-positive tumor cells $(14,15)$, it may preferentially eradicate HER2-overexpressing cells, resulting in the selective survival of HER2-negative tumor cells. In addition, gastric cancer has been reported to have greater heterogenicity of HER2 expression than breast cancer (16, 17). Treatment-induced change in HER2 status may occur more frequently in gastric cancer because HER2-negative tumor cells would become the dominant population in tumors after HER2-targeted therapy. Expression of other receptor tyrosine kinases (RTKs) might be another mechanism that could drive resistance to molecularly targeted therapy through proliferation of non-targeted tumor 
cells after treatment (18). Tumors might either initially coexpress multiple RTKs or shift their proliferative dependency onto other RTKs following molecularly-targeted therapy. Indeed, it has been reported that gastric cancer may coexpress HER2, epidermal growth factor receptor (EGFR), and hepatocyte growth factor receptor (MET) $(19,20)$.

Although several mechanisms have been proposed to explain the results of second-line HER2-targeted therapy in gastric cancer, the reason why HER2-targeted therapy has not shown clinical advantage even in patients not treated with HER2-targeted therapy remains elusive. In this study, we focused on patients with gastric cancer who received preoperative chemotherapy and aimed to examine the changes in HER2 expression status and amplification of $E G F R$ and MET, not only after HER2-targeted therapy, but also after cytotoxic chemotherapy alone.

\section{Materials and Methods}

Patients. Twenty-five patients with gastric cancer who received preoperative chemotherapy between 2009 and 2015 at the Department of Surgery and Science, Kyushu University Hospital were analyzed. Patients who received neoadjuvant chemotherapy for a resectable tumor and who were converted to surgical resection after chemotherapy were included. Two patients enrolled in a clinical trial were also included in this study. Informed consent was obtained from all patients. The local Ethics Committees of Kyushu University (Study number, 28-68) and Chugai Pharmaceutical Co., Ltd. (Study number, E181) approved the study.

Immunohistochemical staining of HER2. Formalin-fixed, paraffinembedded pre-and post-treatment tumor samples were examined for HER2 expression using immunohistochemistry (IHC). After deparaffinization, sections were treated with Target Retrieval Solution (pH 6.0; Dako, Agilent, Santa Clara, CA, USA) in a microwave at $95^{\circ} \mathrm{C}$ for $40 \mathrm{~min}$. Slides were then cooled for $30 \mathrm{~min}$ at room temperature and treated with methanol containing $3 \% \mathrm{H}_{2} \mathrm{O}_{2}$ to block endogenous peroxidase activity. After incubation with $10 \%$ goat serum for $10 \mathrm{~min}$, slides were incubated with an antibody to HER2 (A0485; Dako) at 1:400 dilution overnight at $4^{\circ} \mathrm{C}$, and incubated with horseradish peroxidase polymer-conjugated secondary antibodies (Dako) for $1 \mathrm{~h}$. Sections were then color-developed with 3, 3'diaminobenzidine, counterstained with $10 \%$ Mayer's hematoxylin, dehydrated, and mounted. HER2 expression was scored according to previously described scoring criteria (21-23) as follows: Score of 0 , no staining or membranous staining in $<10 \%$ of tumor cells (surgical specimen) or fewer than five cohesive tumor cells (biopsy specimen); score of $1+$, weak or detectable staining in only one part of the membrane in $\geq 10 \%$ of tumor cells (surgical specimen) or at least five cohesive tumor cells (biopsy specimen); score of $2+$, weak to moderate complete or basolateral membranous staining in $\geq 10 \%$ of tumor cells (surgical specimen) or at least five cohesive tumor cells (biopsy specimen); score of $3+$, moderate to strong complete or basolateral membranous staining in $\geq 10 \%$ of tumor cells (surgical specimen) or at least five cohesive tumor cells (biopsy specimen).

Multicolor fluorescence in situ hybridization (FISH) of EGFR, MET, and HER2. Formalin-fixed, paraffin-embedded tumor samples were examined for HER2, EGFR and MET amplification using FISH. A multicolor FISH probe [EGFR (Cy 5.5)/MET (TexRed)/HER2 (fluorescein isothiocyanate)] was constructed by GSP Laboratory (Kobe, Japan). FISH analysis was performed using pretreatment kit II (GSP Laboratory) according to the manufacturer's instructions. In cases where multicolor FISH signals were faint, samples were re-analyzed using the following dual color FISH probes: HER2/CEN17, EGFR/CEN7, and MET/CEN7 (GSP Laboratory). In all cases, at least 20 cells from more than three different regions of a specimen were examined. HER2-amplified cases were defined as those with an average HER2 gene copy number $\geq 6$ signals per cell or the presence of gene clusters (24). EGFR- or METamplified cases were defined as these with gene copy number $\geq 6$ signals per cell in $\geq 40 \%$ of cells, $\geq 15$ signals per cell in $\geq 10 \%$ of cells, or the presence of gene clusters in $\geq 10 \%$ of cells (25). Fluorescence image acquisition was performed using a Nikon A1R confocal imaging system (Nikon Corporation, Tokyo, Japan). The objective lens was an oil immersion Plan-Apo $\times 60$ numerical aperture 1.40 lens (Nikon).

\section{Results}

HER2 expression and amplification in patients with gastric cancer who had received preoperative chemotherapy. In 25 patients with gastric cancer who had received preoperative chemotherapy, there were five patients with preoperative biopsy samples that were HER $23+$ and one patient who was HER2 2+ with HER2 FISH amplification, and thus considered HER2-positive. In order to examine changes in HER2 status after chemotherapy, we assessed the surgical specimens of these six cases of HER 2 expression, and also performed FISH for EGFR/MET/HER 2 amplification in preand post-treatment specimens. As shown in Table I, all these specimens had HER2 amplification in the concordant region of the tumor (Figures 1 and 2). Neither EGFR nor MET were amplified in any of their pre- and post-treatment specimens.

Figure 1. Immunohistochemical (IHC) staining of human epidermal growth factor receptor 2 (HER2), and fluorescence in situ hybridization (FISH) of epidermal growth factor receptor (EGFR)/hepatocyte growth factor receptor (MET)/HER2 in a case that received trastuzumab in combination with preoperative chemotherapy (patient 1 in Table I). a$d$ : Pre-treatment biopsy specimen. $e$ - $k$ : Post-treatment surgical resected specimen from the same patient. $a, b, e, f, i$ : HER2 IHC staining (magnification: $a ; \times 3, b, f, i ; \times 60, e ; \times 2.5) . c, g, j:$ Hematoxylin and eosin staining (magnification: $\times 60) . d, h, k:$ FISH signals of EGFR/MET/HER2 (magnification: $\times 500$ ). FISH was performed with a probe for EGFR/MET/HER2 in the same region as HER2 IHC staining. EGFR, MET and HER2 gene signals are represented as blue, red, and green, respectively. HER2 IHC score was 3+ in pre-and post-treatment specimens. HER2 amplification was observed in the same region as HER2 IHC staining, whereas no EGFR or MET amplification was observed. 


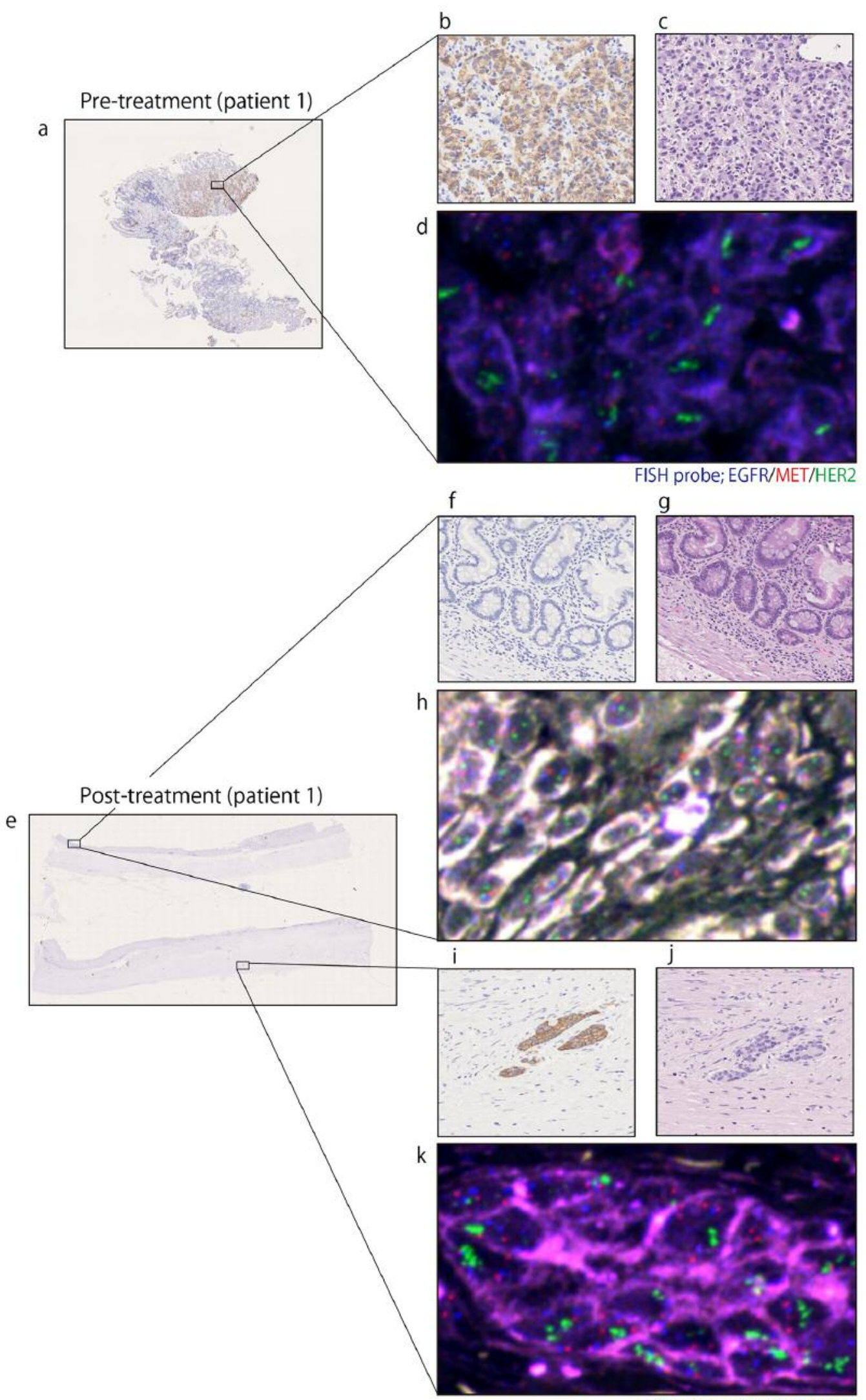

FISH probe; EGFR/MET/HER2 
Changes in HER2 expression and amplification after preoperative chemotherapy. In the six patients who were initially HER2-positive, three patients were treated with trastuzumab in combination with chemotherapy; the other three patients were treated with cytotoxic chemotherapy alone, either S-1, docetaxel, or cisplatin (Table I). The details of the therapy regimens used are also summarized in Table I. Patient 1 treated with trastuzumab in combination with chemotherapy had an initial HER2 IHC score of $3+$ and HER2 gene amplification. After treatment, HER2 expression and amplification were retained in the surgical specimen from the same patient (Table I; Figure 1). In the posttreatment specimen of this case, HER2-positive tumor cells were observed in the mid-portion of the tissue and HER2negative tumor cells were seen in the epithelial portion (Figure 1). Two other patients who had received trastuzumab in combination with chemotherapy showed a decrease or loss of HER2 expression and amplification in post-treatment surgical specimens (patients 2 and 3 in Table I). We also found that in all three cases treated with cytotoxic chemotherapy alone, HER2 expression was lost (IHC score 0) after treatment (Figure 2, patients 4-6 in Table I). In their post-treatment specimens, loss of HER2 gene amplification was also confirmed in all three cases using FISH. Results are summarized in Table I.

\section{Discussion}

Since trastuzumab demonstrated a significant overall survival advantage as first-line therapy for advanced HER2-positive gastric cancer (6), the HER2 signaling pathway is considered to be a driver pathway of proliferation in HER2-positive gastric tumor cells. Although HER2-targeted therapy has been commonly used in second-line treatment of HER2-positive breast cancer (26), it has failed to be established as second-line treatment in gastric cancer. Consistent with previous studies in gastric cancer (11-13), we found that two out of three patients with HER2-positive disease treated with trastuzumab in combination with chemotherapy were converted to HER2negative. In addition, our data suggest that cytotoxic chemotherapy can also lead to loss of HER2-positive tumor cells. The loss of HER2 was confirmed by both protein expression and gene amplification analyses, suggesting that the loss of HER2 expression observed was not due to inappropriate IHC staining conditions that would affect IHC scores (27).

In breast cancer, Guarneri et al. reported that HER2 loss was observed more frequently after cytotoxic chemotherapy alone than after chemotherapy in combination with antiHER2 targeted therapy (40\% versus 14.7\%) (9). Although the reason for this phenomenon observed in the current study and in the breast cancer study is unclear, several preclinical studies showed that HER2 overexpression would promote proliferation of tumor cells $(28,29)$. Therefore, one possible explanation for cytotoxic chemotherapy-induced loss of HER2 is that HER2-positive gastric cancer cells may proliferate faster than other tumor cells, therefore, they would be more sensitive to cytotoxic therapies. Indeed, several clinical studies support the hypothesis that HER2positive tumors are more sensitive to chemotherapy $(30,31)$, suggesting that, like HER2-targeted therapy, cytotoxic therapy may also preferentially eliminate HER2-positive clones, resulting in loss of HER2 positivity. This finding may provide a possible explanation for the result of the GATSBY trial, in which T-DM1 did not show superior clinical benefit compared with taxane in patients who were previously treated with or without HER2-targeted therapy.

Because it has been shown that molecular heterogeneity and receptor co-amplification can drive resistance to targeted therapies (18), we investigated whether the tumors had coamplification of EGFR or MET and whether amplification would be affected by chemotherapy. In our data, neither EGFR nor MET were amplified in pre-and post-treatment specimens, suggesting that EGFR- or $M E T$-amplified tumor cells did not pre-exist or arise during chemotherapy treatment in these cases. However, we cannot rule out the involvement of other RTKs or downstream signaling factors that were previously reported to be amplified or overexpressed in gastric cancer $(32,33)$.

Our work has certain limitations. Firstly, since our results are based on a small sample size, it is difficult to estimate the rate of change of HER2 expression after chemotherapy statistically. Secondly, discordance of HER2 expression between biopsy and surgical specimens may also have influenced the results $(34,35)$. Biopsy specimens may fail to reflect HER2 expression in the whole tumor. Thus, there is still the possibility that we overestimated HER2 expression in pre-treatment specimens. Therefore, further comprehensive assessments are warranted.

Figure 2. Immunohistochemical (IHC) staining of human epidermal growth factor receptor 2 (HER2), and fluorescence in situ hybridization (FISH) of epidermal growth factor receptor (EGFR)/hepatocyte growth factor receptor (MET)/HER2 in a case that received cytotoxic preoperative chemotherapy (patient 6 in Table I). a-g: Pre-treatment biopsy specimen. $h-k$ : Post-treatment surgical resected specimen from the same patient. $a, b, e, h, i: H E R 2$ IHC staining (magnification: $a$; $\times 3, b, e, i ; \times 100, h ; \times 2.5) . c, f, j:$ Hematoxylin and eosin staining (magnification: $\times 100) . d, g, k:$ FISH signals of EGFR/MET/HER2 (magnification: $\times 500$ ). FISH was performed with a probe for EGFR/MET/HER2 in the same region as HER2 IHC staining. EGFR, MET and HER2 gene signals are represented as blue, red, and green, respectively. HER 2 IHC score was $3+$ in the pre-treatment specimen and 0 in the post-treatment specimen. HER2 amplification was observed in the same region as HER2 IHC staining, whereas no EGFR or MET amplification was observed. 


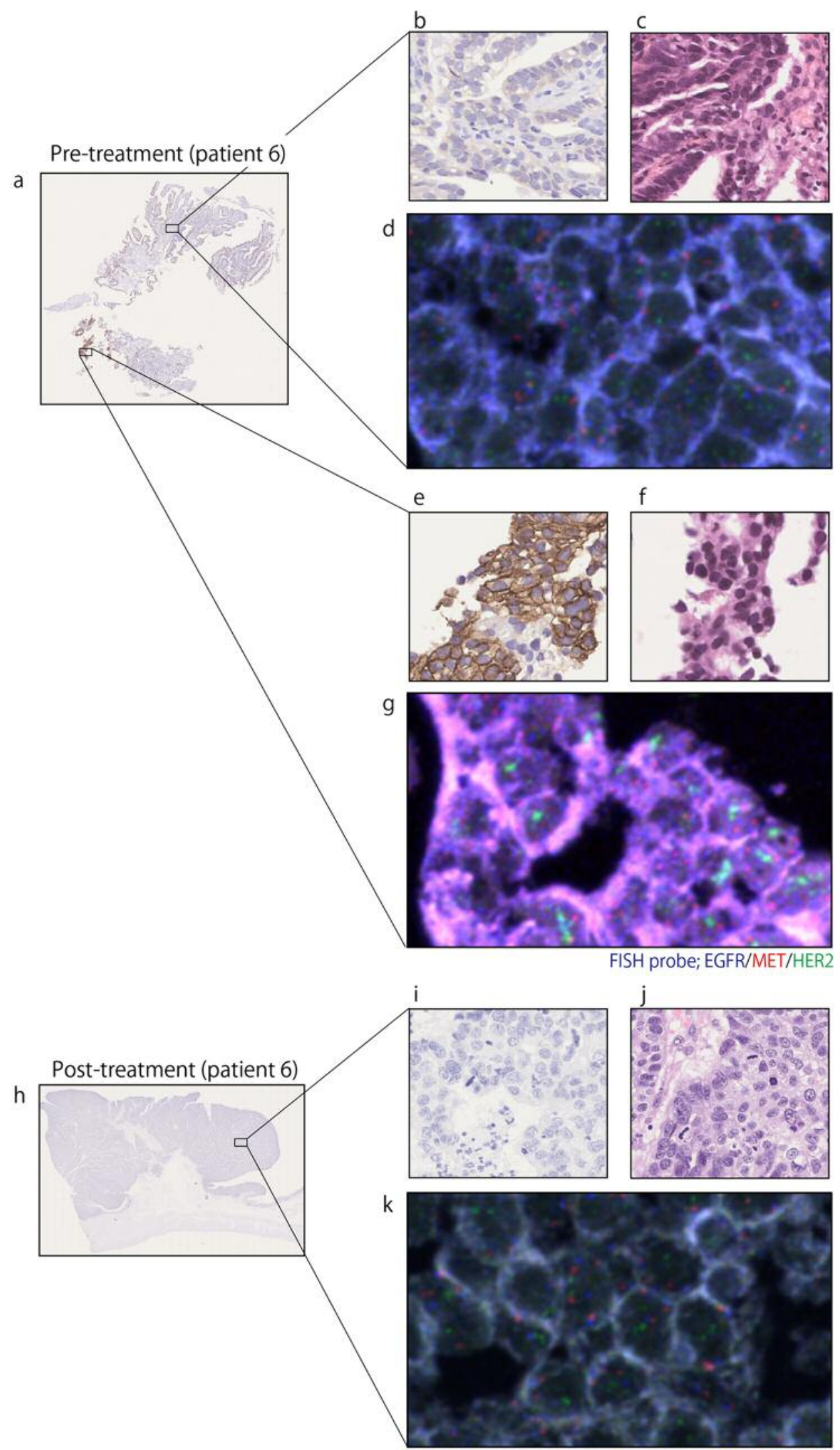

FISH probe; EGFR/MET/HER2 


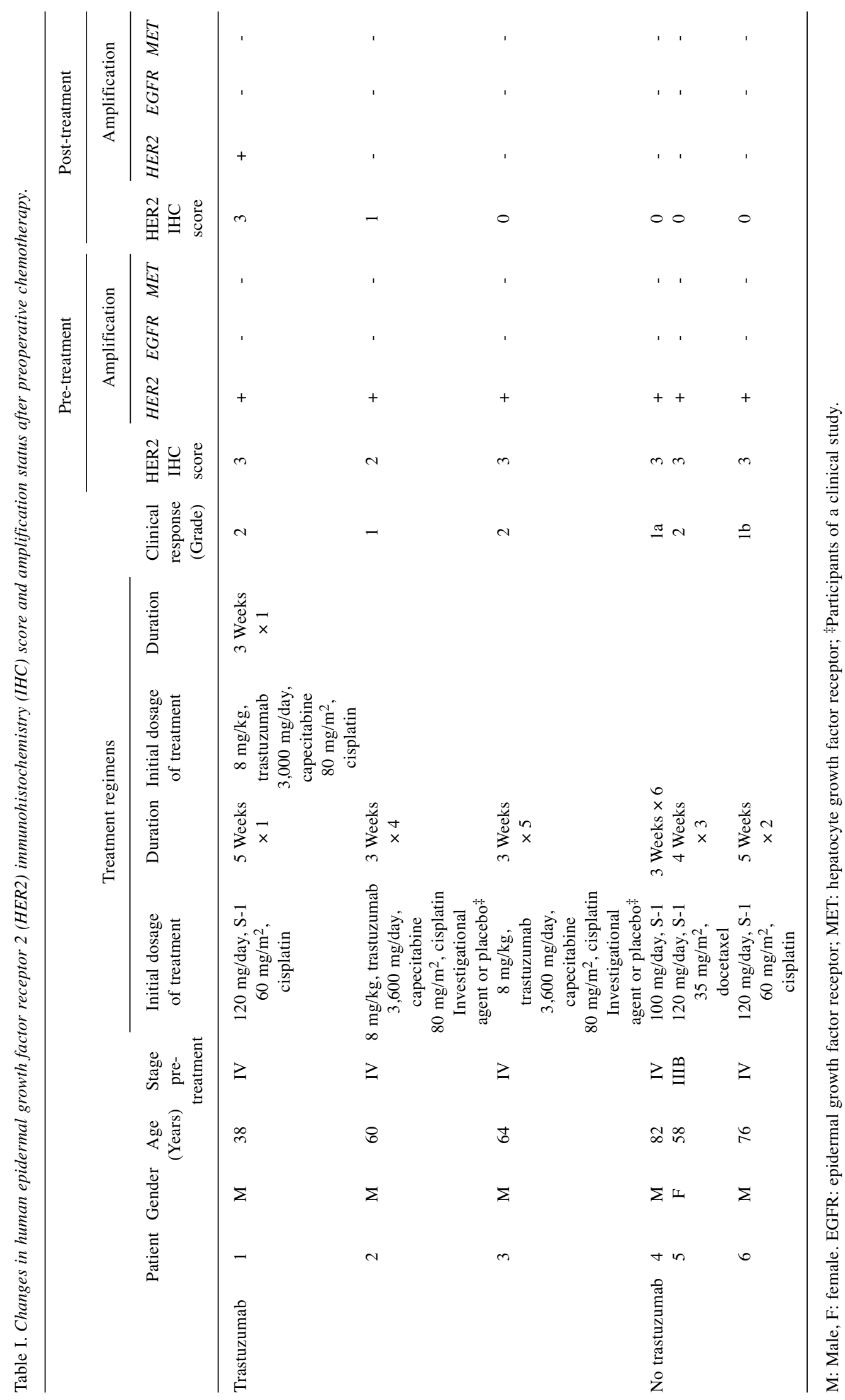


In conclusion, we assessed HER2 status after preoperative chemotherapy and found that cytotoxic chemotherapy alone could lead to loss of HER2 expression and gene amplification. Our data suggest that even in cases that have not previously received HER2-targeted therapy, it is critically important to reassess HER2 expression prior to treatment with HER2-targeted therapy. In order to accurately evaluate efficacy of second-line HER2-targeted therapy in gastric cancer, future clinical trials need to be designed, such that only patients who remain HER2-positive after previous chemotherapy treatment are eligible.

\section{Conflicts of Interest}

S. Shu is an employee of Chugai Pharmaceutical Co. Ltd., M. Iimori is a staff member of an endowed course at Kyushu University funded by a donation from Taiho Pharmaceutical Co., Ltd. All other Authors have no conflicts of interest to declare.

\section{Acknowledgements}

The Authors thank M. Nakajima and Y. Kubota for their expert technical assistance.

\section{References}

1 Van Cutsem E, Kang Y, Chung H, Shen L, Sawaki A, Lordick F, Hill J, Lehle M, Feyereislova A and Bang Y: Efficacy results from the ToGA trial: A phase III study of trastuzumab added to standard chemotherapy (CT) in first-line human epidermal growth factor receptor 2 (HER2)-positive advanced gastric cancer (GC). J Clin Oncol 27: LBA4509-LBA4509, 2009.

2 Gravalos $\mathrm{C}$ and Jimeno A: HER2 in gastric cancer: A new prognostic factor and a novel therapeutic target. Ann Oncol 19: 1523-1529, 2008.

3 He C, Bian XY, Ni XZ, Shen DP, Shen YY, Liu H, Shen ZY and Liu Q: Correlation of human epidermal growth factor receptor 2 expression with clinicopathological characteristics and prognosis in gastric cancer. World J Gastroenterol 19: 21712178,2013

4 Kim KC, Koh YW, Chang HM, Kim TH, Yook JH, Kim BS, Jang SJ and Park YS: Evaluation of HER2 protein expression in gastric carcinomas: Comparative analysis of 1,414 cases of whole-tissue sections and 595 cases of tissue microarrays. Ann Surg Oncol 18: 2833-2840, 2011.

5 Otsu H, Oki E, Ikawa-Yoshida A, Kawano H, Ando K, Ida S, Kimura Y, Aishima S, Saeki H, Morita M, Kohnoe S, Oda Y and Maehara Y: Correlation of HER2 expression with clinicopathological characteristics and prognosis in resectable gastric cancer. Anticancer Res 35: 2441-2446, 2015.

6 Bang YJ, Van Cutsem E, Feyereislova A, Chung HC, Shen L, Sawaki A, Lordick F, Ohtsu A, Omuro Y, Satoh T, Aprile G, Kulikov E, Hill J, Lehle M, Ruschoff J, Kang YK and To GATI: Trastuzumab in combination with chemotherapy versus chemotherapy alone for treatment of HER2-positive advanced gastric or gastro-oesophageal junction cancer (ToGA): A phase 3, open-label, randomised controlled trial. Lancet 376: 687-697, 2010.
7 Satoh T, Xu RH, Chung HC, Sun GP, Doi T, Xu JM, Tsuji A, Omuro Y, Li J, Wang JW, Miwa H, Qin SK, Chung IJ, Yeh KH, Feng JF, Mukaiyama A, Kobayashi M, Ohtsu A and Bang YJ: Lapatinib plus paclitaxel versus paclitaxel alone in the secondline treatment of HER2-amplified advanced gastric cancer in Asian populations: TyTAN-a randomized, phase III study. J Clin Oncol 32: 2039-2049, 2014.

8 Thuss-Patience PC, Shah MA, Ohtsu A, Van Cutsem E, Ajani JA, Castro H, Mansoor W, Chung HC, Bodoky G, Shitara K, Phillips GDL, van der Horst T, Harle-Yge ML, Althaus BL and Kang YK: Trastuzumab emtansine versus taxane use for previously treated HER2-positive locally advanced or metastatic gastric or gastro-oesophageal junction adenocarcinoma (GATSBY): An international randomised, open-label, adaptive, phase 2/3 study. Lancet Oncol 18: 640-653, 2017.

9 Guarneri V, Dieci MV, Barbieri E, Piacentini F, Omarini C, Ficarra G, Bettelli S and Conte PF: Loss of HER2 positivity and prognosis after neoadjuvant therapy in HER2-positive breast cancer patients. Ann Oncol 24: 2990-2994, 2013.

10 Mittendorf EA, Wu Y, Scaltriti M, Meric-Bernstam F, Hunt KK, Dawood S, Esteva FJ, Buzdar AU, Chen H, Eksambi S, Hortobagyi GN, Baselga J and Gonzalez-Angulo AM: Loss of HER2 amplification following trastuzumab-based neoadjuvant systemic therapy and survival outcomes. Clin Cancer Res 15: 7381-7388, 2009.

11 Ishimine Y, Goto A, Watanabe Y, Yajima H, Nakagaki S, Yabana T, Adachi T, Kondo Y and Kasai K: Loss of HER2 positivity after trastuzumab in HER2-positive gastric cancer: Is change in HER2 status significantly frequent? Case Rep Gastrointest Med 2015: 132030, 2015.

12 Pietrantonio F, Caporale M, Morano F, Scartozzi M, Gloghini A, De Vita F, Giommoni E, Fornaro L, Aprile G, Melisi D, Berenato R, Mennitto A, Volpi CC, Laterza MM, Pusceddu V, Antonuzzo L, Vasile E, Ongaro E, Simionato F, de Braud F, Torri V and Di Bartolomeo M: HER2 loss in HER2-positive gastric or gastroesophageal cancer after trastuzumab therapy: Implication for further clinical research. Int J Cancer 139: 28592864, 2016.

13 Seo S, Ryu M-H, Ahn JY, Park Y, Park SR, Ryoo B-Y, Park YS, Lee GH, Jung H-Y and Kang Y-K: Loss of HER2 positivity after anti-HER2 chemotherapy in HER2-positive gastric cancer patients: Results of GASTric cancer HER2 reassessment study 3 (GASTHER3). J Clin Oncol 35: 27-27, 2017.

14 Baselga J, Norton L, Albanell J, Kim YM and Mendelsohn J: Recombinant humanized anti-HER2 antibody (Herceptin) enhances the antitumor activity of paclitaxel and doxorubicin against HER2/neu-overexpressing human breast cancer xenografts. Cancer Res 58: 2825-2831, 1998.

15 Fujimoto-Ouchi K, Sekiguchi F, Yasuno H, Moriya Y, Mori K and Tanaka Y: Antitumor activity of trastuzumab in combination with chemotherapy in human gastric cancer xenograft models. Cancer Chemother Pharmacol 59: 795-805, 2007.

16 Lee HE, Park KU, Yoo SB, Nam SK, Park DJ, Kim HH and Lee HS: Clinical significance of intratumoral HER2 heterogeneity in gastric cancer. Eur J Cancer 49: 1448-1457, 2013.

17 Yang J, Luo H, Li Y, Li J, Cai Z, Su X, Dai D, Du W, Chen T and Chen $\mathrm{M}$ : Intratumoral heterogeneity determines discordant results of diagnostic tests for human epidermal growth factor receptor (HER) 2 in gastric cancer specimens. Cell Biochem Biophys 62: 221-228, 2012. 
18 Kwak EL, Ahronian LG, Siravegna G, Mussolin B, Godfrey JT, Clark JW, Blaszkowsky LS, Ryan DP, Lennerz JK, Iafrate AJ, Bardelli A, Hong TS and Corcoran RB: Molecular heterogeneity and receptor coamplification drive resistance to targeted therapy in $M E T$-amplified esophagogastric cancer. Cancer Discov 5: 1271-1281, 2015.

19 Fuse N, Kuboki Y, Kuwata T, Nishina T, Kadowaki S, Shinozaki E, Machida N, Yuki S, Ooki A, Kajiura S, Kimura T, Yamanaka T, Shitara K, Nagatsuma AK, Yoshino T, Ochiai A and Ohtsu A: Prognostic impact of HER2, EGFR and $c$-MET status on overall survival of advanced gastric cancer patients. Gastric Cancer 19: 183-191, 2016.

20 Nagatsuma AK, Aizawa M, Kuwata T, Doi T, Ohtsu A, Fujii H and Ochiai A: Expression profiles of HER2, EGFR, MET and FGFR2 in a large cohort of patients with gastric adenocarcinoma. Gastric Cancer 18: 227-238, 2015.

21 Abrahao-Machado LF and Scapulatempo-Neto C: HER2 testing in gastric cancer: An update. World J Gastroenterol 22: 46194625, 2016.

22 Hofmann M, Stoss O, Shi D, Buttner R, van de Vijver M, Kim W, Ochiai A, Ruschoff J and Henkel T: Assessment of a HER2 scoring system for gastric cancer: Results from a validation study. Histopathology 52: 797-805, 2008.

23 Ruschoff J, Dietel M, Baretton G, Arbogast S, Walch A, Monges G, Chenard MP, Penault-Llorca F, Nagelmeier I, Schlake W, Hofler $\mathrm{H}$ and Kreipe HH: HER2 diagnostics in gastric cancer-guideline validation and development of standardized immunohistochemical testing. Virchows Arch 457: 299-307, 2010.

24 Hanna WM, Ruschoff J, Bilous M, Coudry RA, Dowsett M, Osamura RY, Penault-Llorca F, van de Vijver M and Viale G: HER2 in situ hybridization in breast cancer: Clinical implications of polysomy 17 and genetic heterogeneity. Mod Pathol 27: 4-18, 2014.

25 Varella-Garcia M, Diebold J, Eberhard DA, Geenen K, Hirschmann A, Kockx M, Nagelmeier I, Ruschoff J, Schmitt M, Arbogast S and Cappuzzo F: EGFR fluorescence in situ hybridisation assay: Guidelines for application to non-small-cell lung cancer. J Clin Pathol 62: 970-977, 2009.

26 Verma S, Miles D, Gianni L, Krop IE, Welslau M, Baselga J, Pegram M, Oh DY, Dieras V, Guardino E, Fang L, Lu MW, Olsen $\mathrm{S}$ and Blackwell K: Trastuzumab emtansine for HER2-positive advanced breast cancer. N Engl J Med 367: 1783-1791, 2012.

27 Yamashita-Kashima Y, Shu S, Yorozu K, Hashizume K, Moriya Y, Fujimoto-Ouchi $\mathrm{K}$ and Harada N: Importance of formalin fixing conditions for HER2 testing in gastric cancer: Immunohistochemical staining and fluorescence in situ hybridization. Gastric Cancer 17: 638-647, 2014
28 Chi F, Wu R, Jin X, Jiang M and Zhu X: HER2 induces cell proliferation and invasion of non-small-cell lung cancer by upregulating COX2 expression via MEK/ERK signaling pathway. OncoTargets and therapy 9: 2709-2716, 2016.

29 Eladdadi A and Isaacson D: A mathematical model for the effects of HER2 overexpression on cell proliferation in breast cancer. Bull Math Biol 70: 1707-1729, 2008.

30 Baselga J, Seidman AD, Rosen PP and Norton L: HER2 overexpression and paclitaxel sensitivity in breast cancer: Therapeutic implications. Oncology 11: 43-48, 1997.

31 Muss HB, Thor AD, Berry DA, Kute T, Liu ET, Koerner F, Cirrincione CT, Budman DR, Wood WC, Barcos $\mathrm{M}$ and Henderson IC: c-ERBB-2 expression and response to adjuvant therapy in women with node-positive early breast cancer. N Engl J Med 330: 1260-1266, 1994.

32 Jia Y-X, Li T-F, Zhang D-D, Fan Z-M, Fan H-J, Yan J, Chen L$\mathrm{J}$, Tang $\mathrm{H}$, Qin $\mathrm{Y}-\mathrm{R}$ and $\mathrm{Li} \mathrm{X}-\mathrm{Y}$ : The coexpression and prognostic significance of c-MET, fibroblast growth factor receptor 2 and human epidermal growth factor receptor 2 in resected gastric cancer: a retrospective study. OncoTarg Ther 9: 5919-5929, 2016.

33 Stahl P, Seeschaaf C, Lebok P, Kutup A, Bockhorn M, Izbicki JR, Bokemeyer C, Simon R, Sauter G and Marx AH: Heterogeneity of amplification of HER2, EGFR, CCND1 and $M Y C$ in gastric cancer. BMC Gastroenterol 15: 7, 2015.

34 Gullo I, Grillo F, Molinaro L, Fassan M, De Silvestri A, Tinelli C, Rugge M, Fiocca R and Mastracci L: Minimum biopsy set for HER2 evaluation in gastric and gastro-esophageal junction cancer. Endosc Int Open 3: E165-E170, 2015.

35 Huang SC, Ng KF, Lee SE, Chen KH, Yeh TS and Chen TC: HER2 testing in paired biopsy and excision specimens of gastric cancer: The reliability of the scoring system and the clinicopathological factors relevant to discordance. Gastric Cancer 19: 176-182, 2016.
Received July 24, 2018

Revised September 11, 2018

Accepted September 13, 2018 